\title{
Restoring Function and Aesthetics in a Class II Division 1 Patient with Amelogenesis Imperfecta: A Clinical Report
}

Cenk Doruk ${ }^{a}$

Firat Ozturk ${ }^{b}$

Fatih Saric

Mehmet Turgut ${ }^{\mathrm{d}}$

\begin{abstract}
Amelogenesis imperfecta (Al) encompasses a complicated group of hereditary conditions that cause developmental alterations in the structure of the enamel in the absence of a systemic disorder. Al primarily affects the quality and/or quantity of dental enamel, and it may affect all or only some of the teeth in the primary and/or permanent dentition. This clinical report describes the oral rehabilitation of a 21-year-old man diagnosed with hypomaturation-type Al. He presented with discolored and mutilated teeth. Cephalometrically, the patient has skeletal class II malocclusion due to mandibular deficiency considered as a result of maxillary constriction. The interdisciplinary approach was followed because of the complex needs of the patient. The aim of treatment was to restore aesthetics, improve malocclusion and masticatory function. Aesthetic and functional expectations were met with metal ceramic restorations. In this report, the interdisciplinary approach for a patient with Al and a malocclusion is described. (Eur J Dent 2011;5:220-228)
\end{abstract}

Key words: Amelogenesis imperfect; Interdisciplinary study; Orthodontic appliance.

Professor and Head, Department of Orthodontics, Faculty of Dentistry, Cumhuriyet University, Sivas, Turkey.

b Assistant Professor, Department of Orthodontics, Faculty of Dentistry, Inonü University, Malatya, Turkey.

c Research Fellow, Department of Prosthodontics, Faculty of Dentistry, Gaziantep University, Gaziantep, Turkey.

d Associate Professor, Private Practice, Kayseri, Turkey.

Corresponding author: Dr. Firat Ozturk Inonü Universitesi, Dishekimligi Fakultesi Ortodonti A.D. 44280, Malatya, Turkey. Phone: +904223411106

Fax: +904223411107

E-mail: dtfiratdgmail.com

\section{INTRODUCTION}

Amelogenesis imperfecta (Al) encompasses a complicated group of hereditary conditions that cause developmental alterations in the structure of the enamel in the absence of a systemic disorder. Al primarily affects the quality and/or quantity of dental enamel. Clinical implications of Al vary according to subtype and its severity, but the main problems are aesthetics, dental sensitivity and loss of vertical dimension. Additionally, in some types of $\mathrm{Al}$ there is an increased prevalence of caries, anterior open bite, delayed eruption, tooth impaction, or associated gingival inflamma- 
tion. Furthermore, nonenamel dental anomalies such as taurodontism, congenitally missing teeth, failure of eruption, root or crown resorption, root malformations, hypercementosis, and dental and skeletal open bite are reported to be associated with Al. ${ }^{1-9} \mathrm{Al}$ may affect all or only some of the teeth in the primary and/or permanent dentition. The formation of enamel is a multistep process, and problems may arise in any one of the steps. In general, development of enamel can be divided into three major stages: (1) elaboration of the organic matrix, (2) mineralization of the matrix, and (3) maturation of the enamel. Al may create non-aesthetic appearance, dental sensitivity, and attrition. Al has an estimated prevalence of approximately $1 / 14,000$ in the United States and, 1/700 in northern Sweden. ${ }^{8-10}$ Investigators have demonstrated the existence of at least 14 different hereditary subtypes of $\mathrm{Al}$, with numerous patterns of inheritance and wide variety of clinical manifestations. On the clinical and radiographic basis alone, three broad groups can be distinguished: (1) hypoplasia, in which the enamel is reduced in quantity but is relatively well-mineralized; (2) hypocalcification, in which enamel is formed in relatively normal amounts but is poorly mineralized; and (3) hypomaturation, in which the final stages of mineralization process are abnormal. ${ }^{9-15}$

Numerous treatments have been described for rehabilitation of $\mathrm{Al}$ in adults and children. ${ }^{16-19}$ Restoration of these defects is important not only because of aesthetic and functional concerns, but also because there may be a positive psychological impact for the patient. ${ }^{10-25}$ Treatment planning for patients with $\mathrm{Al}$ is related to many factors including the age and socioeconomic status of the patient, the type and severity of the disorder, and the intraoral situation at the time the treatment is planned. An interdisciplinary approach is necessary to evaluate, diagnose, and resolve aesthetic and functional problems using a combination of orthodontic, prosthodontic and restorative treatments. This clinical report describes the interdisciplinary approach for a patient with Al and a malocclusion.

\section{CASE REPORT}

A 21year old man who was self-conscious about his teeth and skeletal appearance referred to the Department of Orthodontic at Cumhuriyet
University. His chief complaints were an extreme sensitivity to hot and cold, dissatisfaction with the appearance of his teeth, and a compromised masticatory function. He sought to improve the appearance of his anterior teeth and his chewing ability.

A detailed dental, medical, and social history was obtained from the patient. Clinical examination of the patient revealed Class II Division I dental relationship with $17 \mathrm{~mm}$ overjet due to maxillary constriction (Figures 1 and 2). The mandibular right and left first molar and left second molar were previously extracted due to caries. The upper left and right deciduous canines and lower right deciduous second lateral and deciduous canine tooth were retained in the jaws, and all premolars and molars had cavities.

Radiographically analysis showed the mandibular right and left third molars, the right second incisor, and the right canine tooth were impacted. In the maxilla, the right and left canines and third molars were impacted. In addition, there was a supernumerary tooth in the left canine region. On the panoramic radiograph, enamel had approximately the same radiodensity as dentin (Figure 3). Following the detailed examination, the patient was diagnosed as having a hypomaturation type of Al.

Cephalometrically, the patient has skeletal Class II malocclusion due to mandibular deficiency considered as a result of maxillary constriction. The mandible was rotated in the posteriorly, which increased the severity of Class II malocclusion (Figure 3).

\section{Treatment objectives}

The main treatment objective was to expand the maxilla with surgically assisted rapid maxillary expansion (SARME) and to guide the eruption of the impacted teeth with full fixed orthodontic therapy. After fixed orthodontic therapy, orthognathic surgery was planned to correct the Class II relationship. After ideal dental and skeletal relationship was gained with orthodontic therapy, metal-ceramic porcelain dentures were planned to improve the patient's appearance. The patient was informed about the treatment plan and informed consent was given.

\section{Treatment progress}

The interdisciplinary approach was followed because of the complex needs of the patient. All 
decayed teeth were restored and the upper right first molar was extracted due to caries before the orthodontic treatment. SARME was performed to expand the skeletally narrow maxilla. An acrylic, fully bonded tooth and tissue-borne rapid maxil- lary expansion appliance containing a Hyrax screw (GAC International, Islandia, New York, USA) was used for expansion. The expansion appliance was activated one-quarter turn daily. After achieving successful expansion, an 0.080 inch Essix reten-

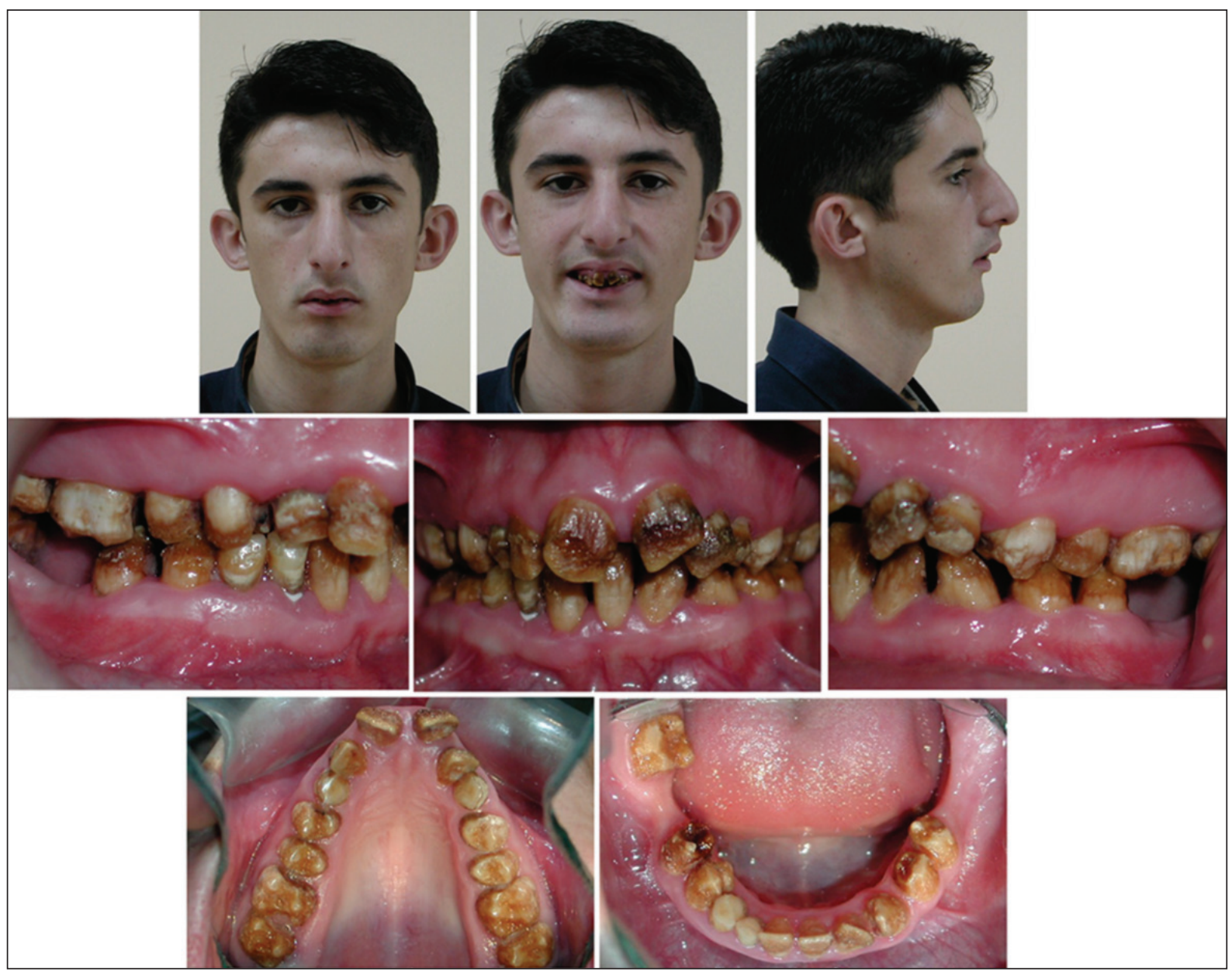

Figure 1. Pretreatment facial and intraoral photographs.
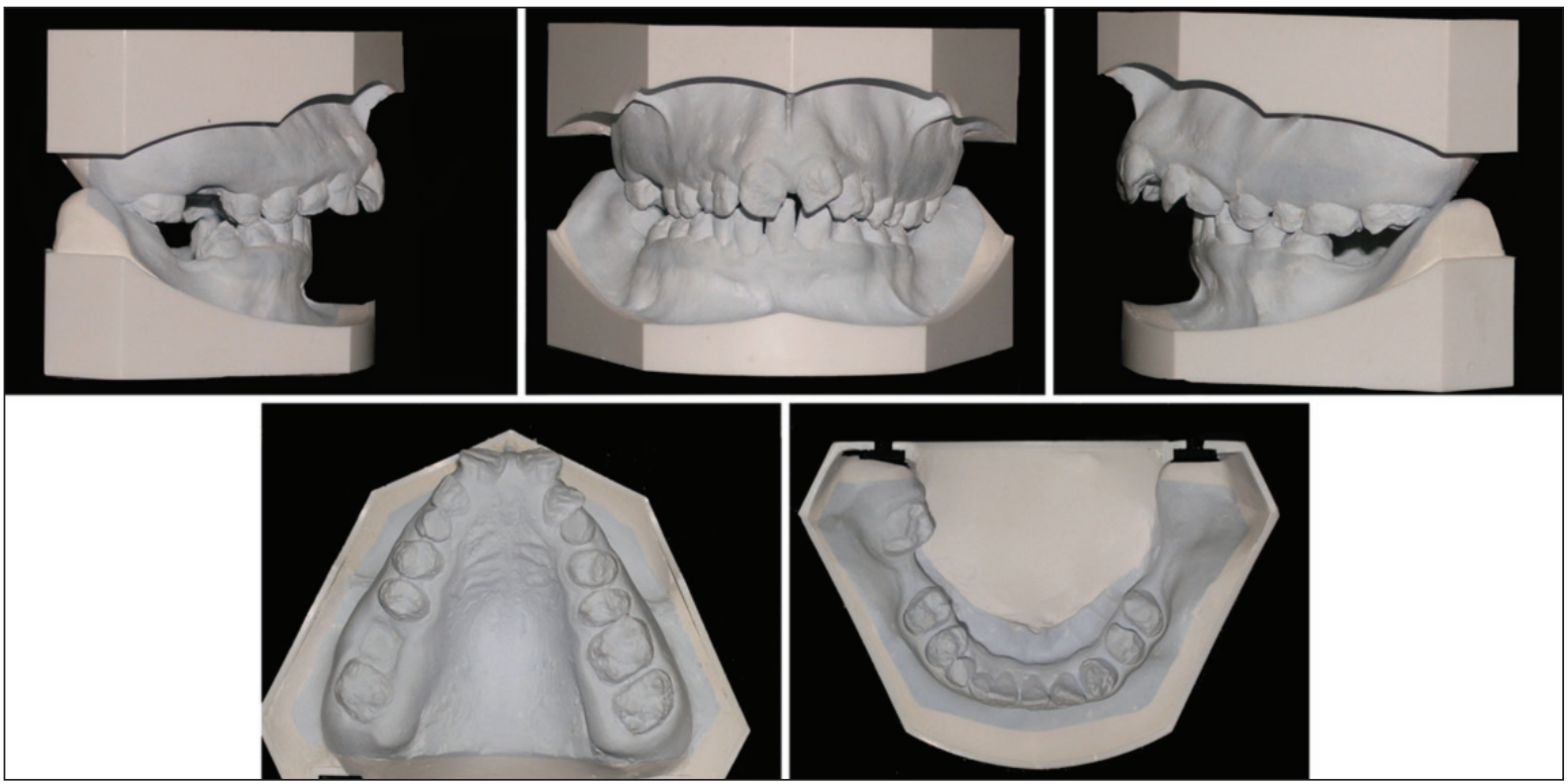

Figure 2. Preatreatment study models. 
tion appliance was used for six months. The patient underwent extraction of the retained primary and supernumerary teeth before placement of the fixed orthodontic appliances. Orthodontic appliances were placed two week after extraction. Teeth were etched for 20 seconds with 37\% phosphoric acid and washed with air-water spray for ten seconds. The surface was thoroughly dried and the Transbond XT sealant was applied to the etched surface and cured with halogen light for ten seconds. Transbond XT paste (3M Unitek, Monrovia, California, USAl was applied to the bracket base and cured again 20 seconds with halogen light. After the bonding light, continuous arch wires were placed. After six months with the continuous arch wires, the patient was referred back to the oral surgeon with continuous $0.016 \times 0.022$ inch stainless steel arch wires in place. Four permanent teeth were exposed surgically and a gold chain was bonded to each individual tooth. The chains were ligated with no eruptive force to the stopped maxillary arch wire with a stainless steel ligature. Eruptive force was applied one week after exposure. A power thread was placed from each gold chain to the arch wire above the impacted tooth. Attachments on the impacted teeth failed several times. Due to the failures and difficulty of per- forming surgery in every failure, a decision was made to extract these impacted teeth $(13,23,42$, and 43). After the extractions orthognathic surgery was planned; however, the patient did not want to undergo surgery because of previous surgical operations. At this stage, the treatment plan was altered. Retractions of upper incisors were done with contraction torquing utility arch $10.016 \times 0.022$ TMAl due to the patient's refusal of the orthognathic surgery. Orthodontic treatment of the patient lasted for approximately 34 months. Both a gingivectomy and gingivoplasty were performed in the maxilla and mandible to adjust the height of the cervical line. The sites were allowed to heal for two weeks. In this period, the patient used 0.040 inch Essix retainers. Maxillary and mandibulary teeth were prepared for metal-ceramic fixed partial dentures and provisional crowns were prepared according to the craniomaxillary and maxillomandibular relationships in the centric relation position. For aesthetic restoration, full mouth metal-ceramic fixed partial dentures were applied after a week.

\section{Treatment results}

Well aligned arches were obtained after orthodontic treatment (Figures 4 and 5). Panoramic

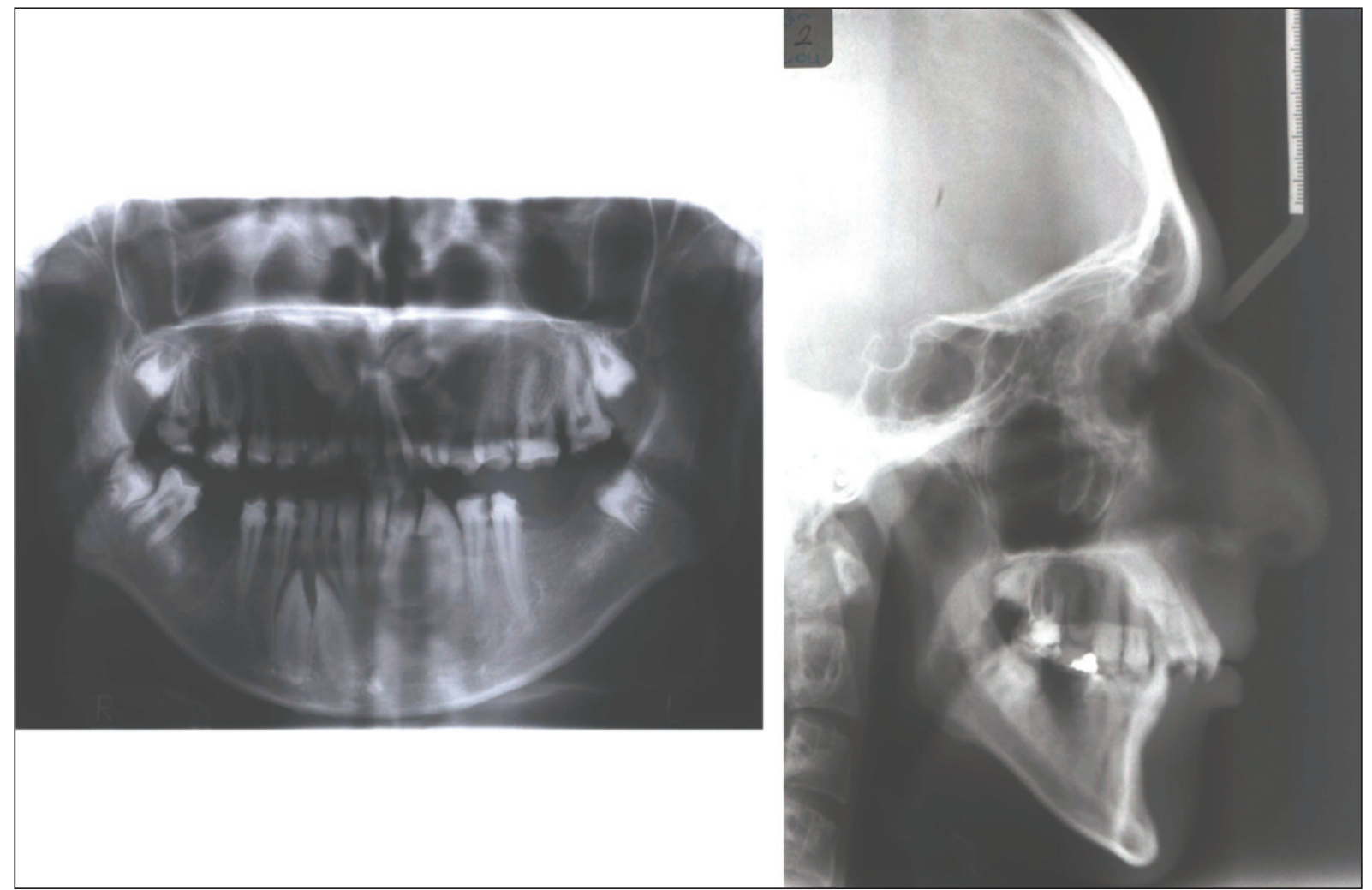

Figure 3. Pretreatment panaromic and cephalometric radiographs. 
radiographs showed no root resorption or periodontal bone loss. Cephalometric measurements showed that Class II skeletal relationship was maintained after treatment (Figures 6 and 7). Although the patient did not accept orthognathic sur- gery, satisfactory treatment results were achieved with a multidisciplinary treatment approach in a patient with Al (Figure 8).

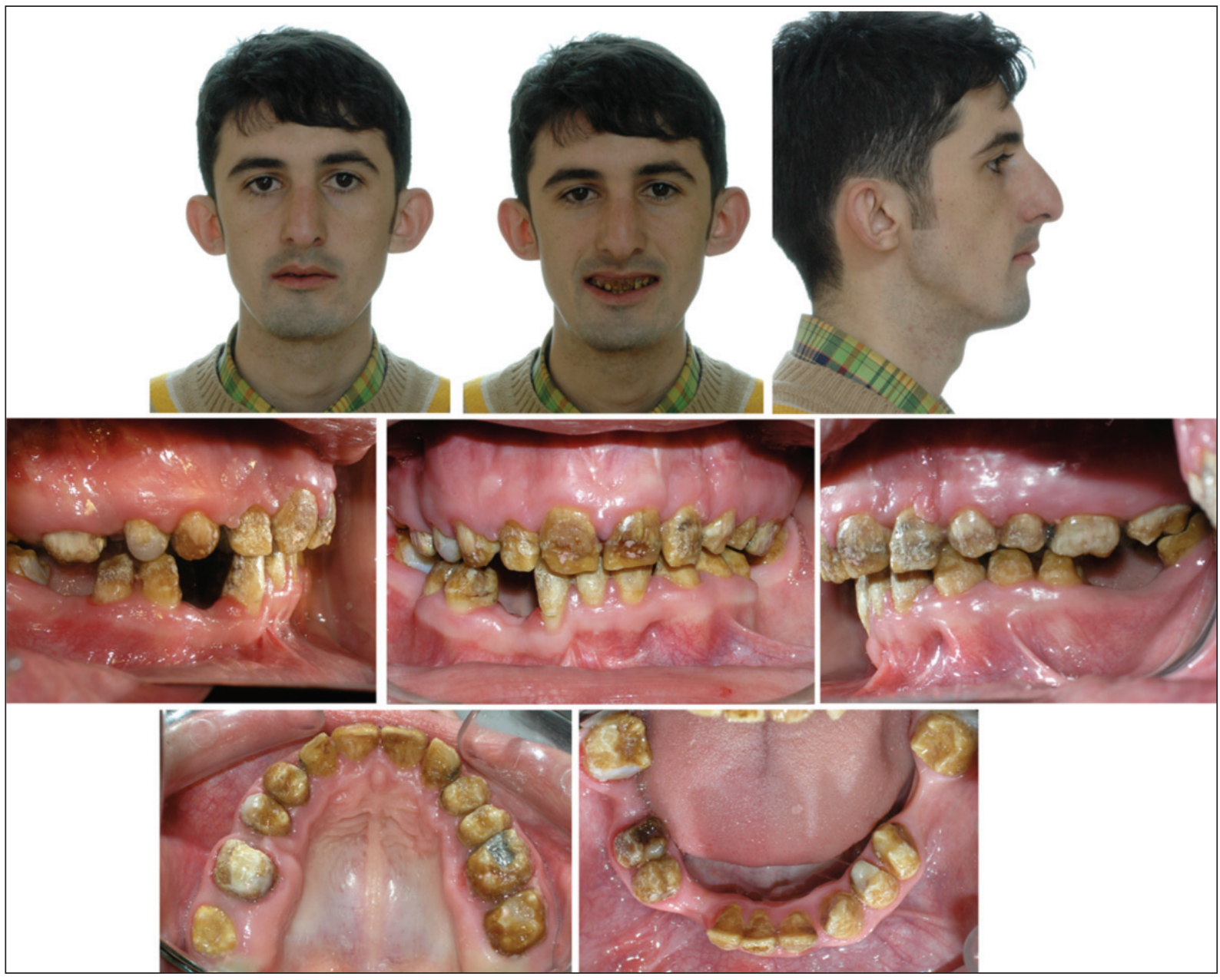

Figure 4. Facial and intraoral photographs after orthodontic treatment.
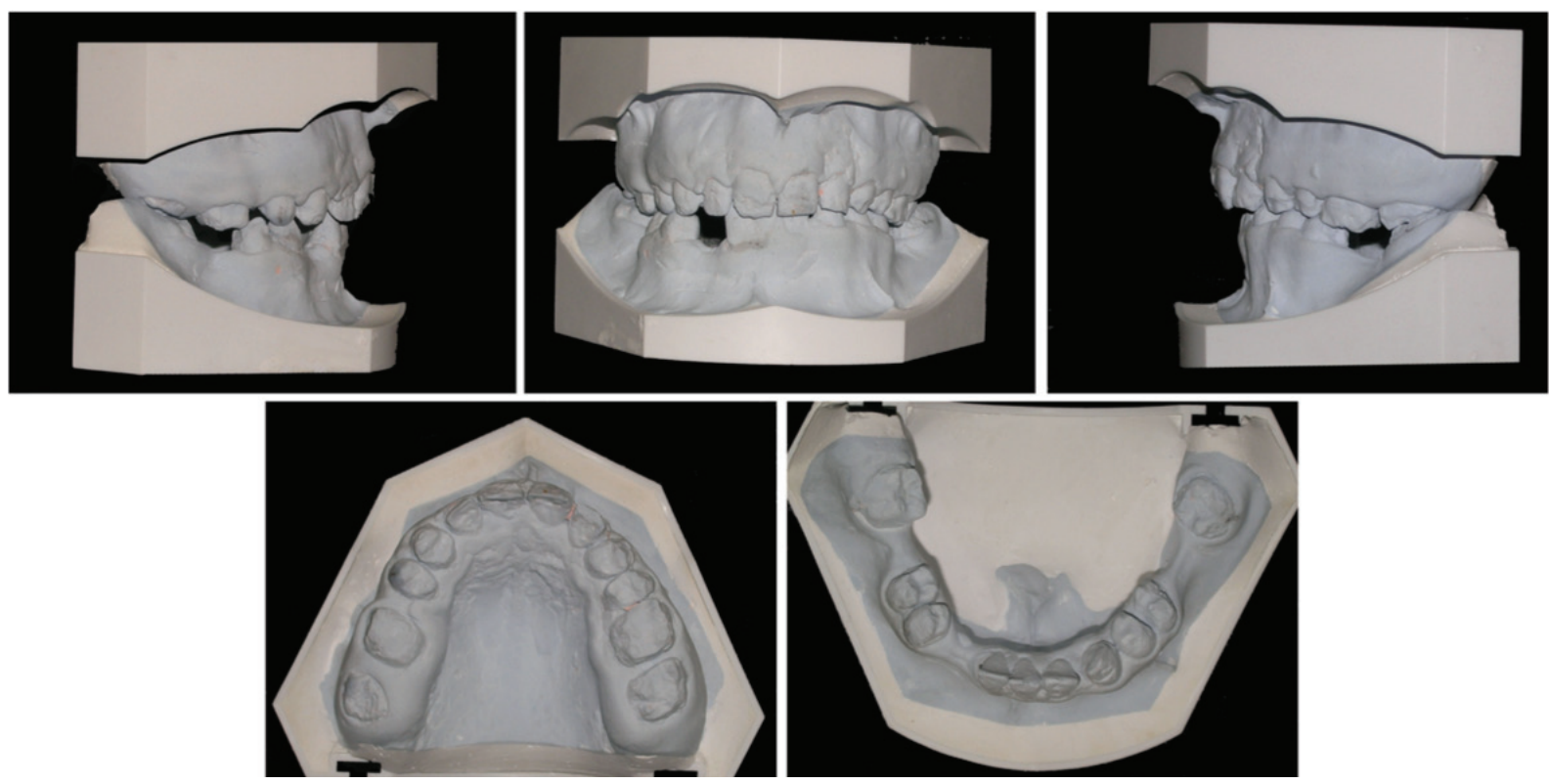

Figure 5. Posttreatment study models. 


\section{DISCUSSION}

Although there are several methods to determine the type of Al using combinations of clinical, radiographic, histological, and genetic criteria, clinicians rely on clinical and radiographic findings when diagnosing and planning treatment for patients with Al. The clinical features distinguish the hypoplastic and hypocalcified types. ${ }^{11,26}$ In the hypoplastic forms, the enamel does not develop to its normal thickness. In the hypocalcified forms, the enamel thickness on the newly erupted teeth closely approaches that of normal teeth, but the enamel is soft, friable, and can easily be removed from dentin. In contrast to hypoplastic types, the hypomaturation types develop enamel of normal thickness. The hypomaturation forms differ from hypocalcification in that the enamel is harder, with a mottled opaque white to yellow-brown or redbrown color, and tends to chip from the underlying dentin rather than wear away. 4,14,26,27

In previous studies, ${ }^{28-30}$ the dentition in patients with Al was generally caries resistant, but teeth showed surface irregularities, discoloration, and excessive attrition resulting in short clinical crowns, a tapered crown form with spacing in the anterior region but tight proximal contacts between adjacent teeth in the posterior regions. ${ }^{31}$
Although patients' dentition showed surface irregularities, discoloration, tight proximal contacts in posterior teeth, and spacing in the anterior region as defined, almost all of the posterior teeth were decayed.

Failure of multiple permanent teeth to erupt into the oral cavity has been described in several Al cases. ${ }^{4,32,33}$ Seow $^{6}$ showed that patients with $\mathrm{Al}$ had six times the tendency of unaffected people to have impaction of permanent teeth and associated anomalies, such as follicular cysts. In addition to this, our case had four impacted teeth $(13,23,42,43)$.

Hoppenreijs et $\mathrm{al}^{31}$ reported that when the maxillary and mandibular transverse dental arch measurements of an Al group were compared with those of a non- Al group, the intermolar, interpremolar and anterior arch widths were smaller in the Al group than in the non-Al group, with the exception of the mandibular interpremolar arch width. The maxillary and mandibular dental arches were more constricted and more omegashaped in the Al groups. Similarly, our patient had a maxillary narrowness.

Rowley et $a^{34}$ reported a large maxillary mandibular plane angle and increased lower facial height conjunction with anterior open bite in $24 \%$ of the patients with hypocalcification (hypomin-

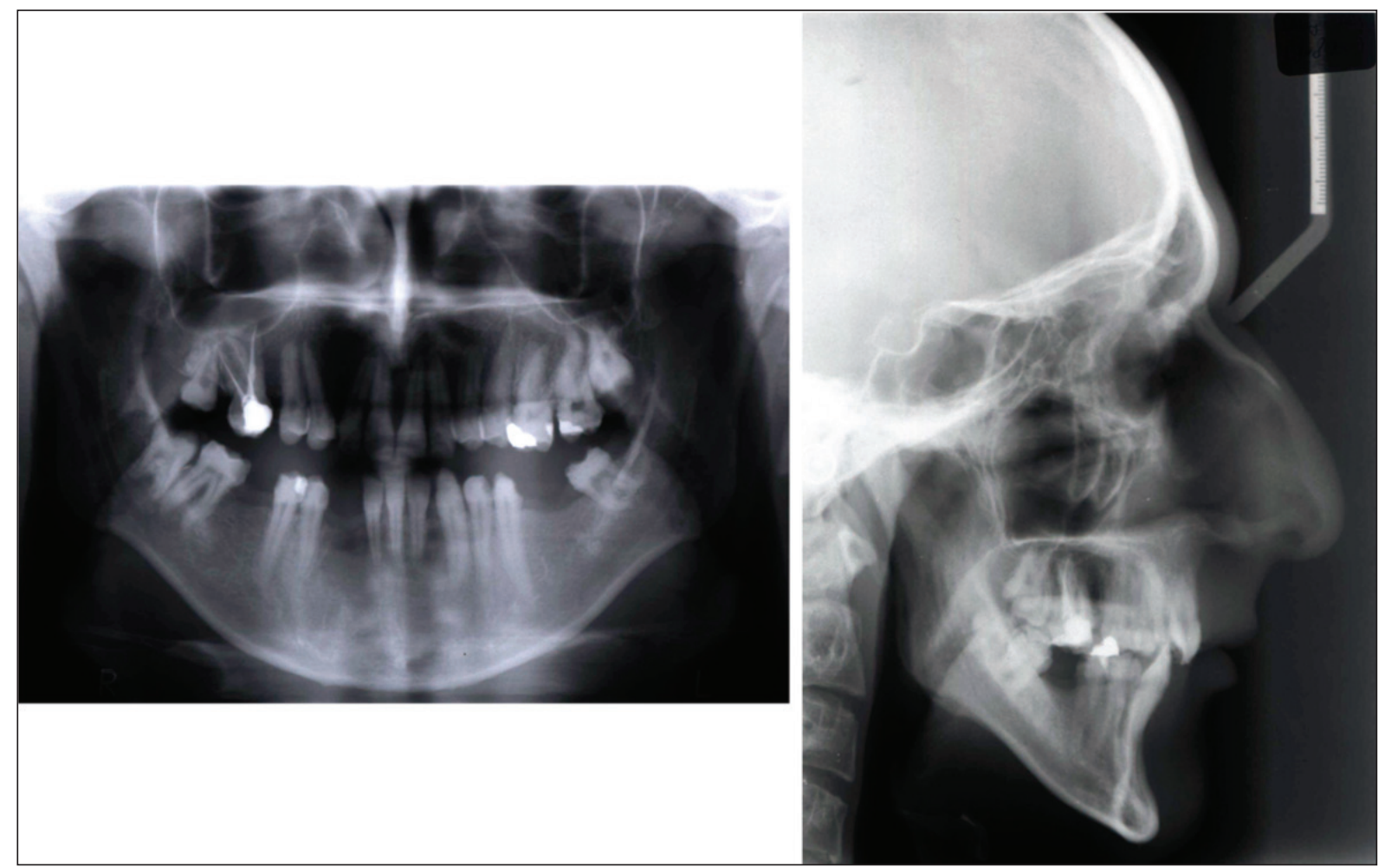

Figure 6. Panaromic and cephalometric radiographs after orthodontic treatment. 


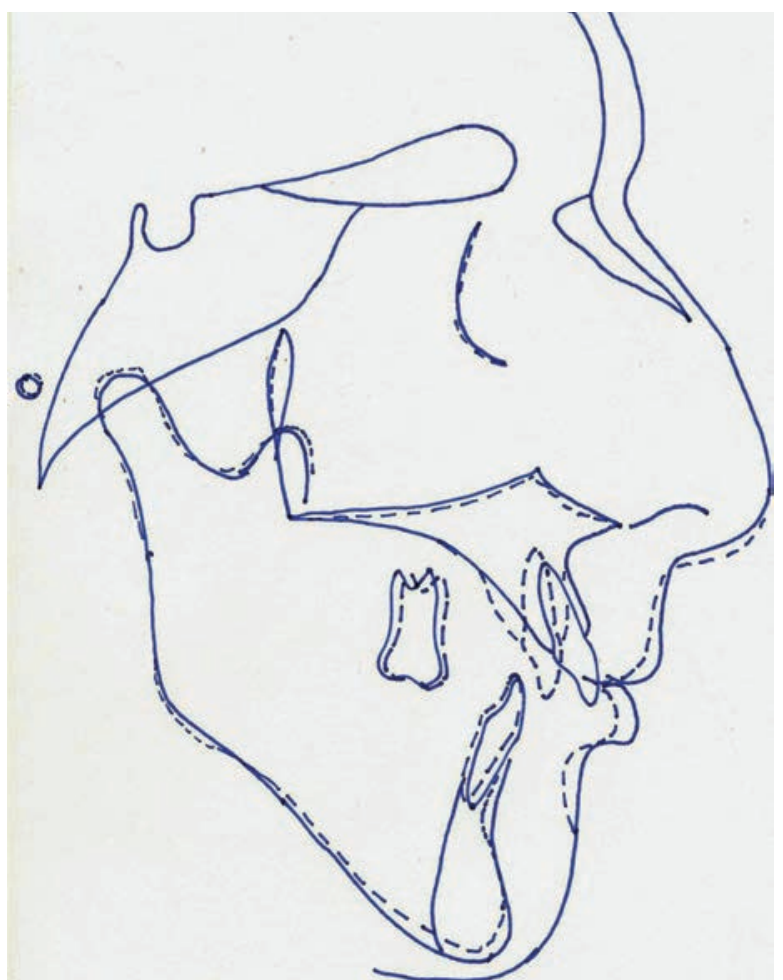

Figure 7. Cephalometric superimposition. eralization) and hypoplastic-types of Al. Anterior open bite was reported in both primary and permanent dentitions of $50 \%$ of the patients with hypoplastic-type $\mathrm{Al}, 30.8 \%$ of the patients with hypomaturation-type $\mathrm{Al}$, and $60 \%$ of hypocalcified-type Al. ${ }^{35}$ Although maxillary mandibular plane angle and lower facial height were increased, our patient had an average bite with increased overjet.

Dental radiographs of Al teeth provide important information for the clinician with respect to the degree of enamel mineralization. Evaluation of enamel density changes in Al teeth are generally made by contrasting the enamel with the dentin; enamel that has a radiopacity similar to or less than that of dentin is considered mineral deficient. $^{2}$ On radiographic examination, enamel had the approximately same density as dentin.

Alignment of the dental arches by using fixed appliances, however, gives rise to special problems because of reduced hardness and thickness of the dental enamel in Al cases. ${ }^{31,36}$ Koyuturk et

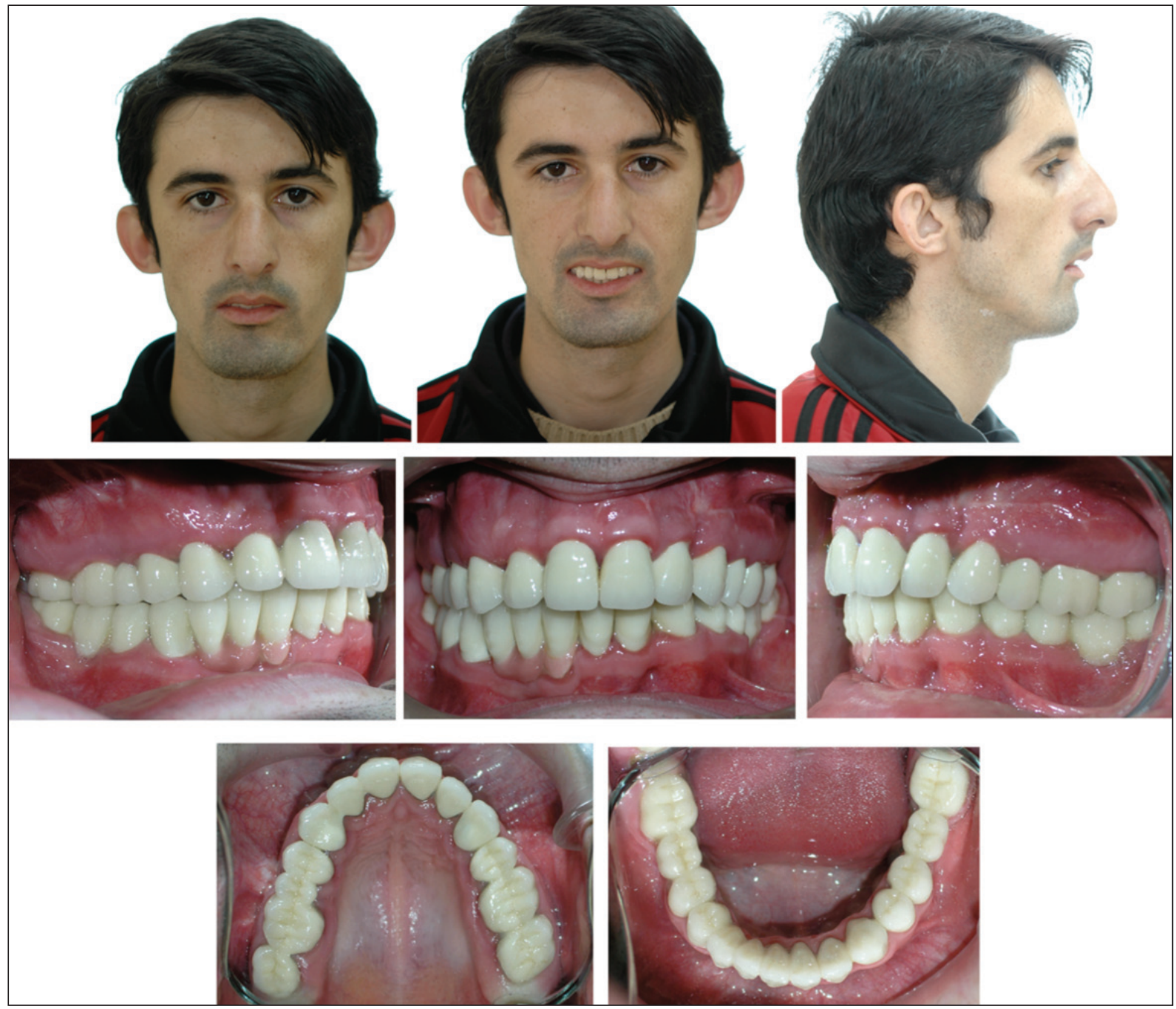

Figure 8. Facial and intraoral radiographs after prosthetics restoration. 
$\mathrm{a}^{37}$ concluded that human enamel affected by Al showed significantly lower micro-shear bond strength when compared to that of sound human enamel. We experienced bonding failure several times in eruption of impacted teeth and during the fixed orthodontic therapy. Although in teeth affected with hypocalcified-Al, enamel shear bond strength may be enhanced with pretreating the tooth surface with 5\% sodium hypoclorite, ${ }^{37-39}$ there is no method to enhance bond strength for the hypomature and hypoplastic types of Al. In addition to this, the unfavorable morphology of the affected and sensitive teeth also makes them inappropriate for removable orthodontic appliances. ${ }^{31}$

There are a number of alternatives for the treatment of teeth affected by Al. Although allceramic fixed partial dentures are more aesthetically pleasing than are metal-ceramic fixed partial dentures, they are more expensive than the others. Therefore, we used metal-ceramic fixed partial dentures.

\section{CONCLUSIONS}

This clinical report describes esthetic and functional rehabilitation of a case of hypomature $\mathrm{Al}$ with the use of orthodontic treatment and metalceramic fixed dentures. Coordinated orthodontic and prosthodontic treatments with careful consideration of patient expectations and requests, were critical for outcome and patient satisfaction. Early treatment of Al patients can prevent progressive damage of dentition and the psychological impact of the condition. Controlled retrospective studies of the prosthodontic management of Al patients and more clinical cases with an ample follow-up period are needed to increase our knowledge of treatment outcomes in patients with Al.

\section{REFERENCES}

1. Atasu M, Biren S, Mumcu G. Hypocalcification type amelogenesis imperfecta in permanent dentition in association with heavily worn primary teeth, gingival hyperplasia, hypodontia and impacted teeth. J Clin Pediatr Dent 1999;23:117-121.

2. Collins MA, Mauriello SM, Tyndall DA, Wright JT. Dental anomalies associated with amelogenesis imperfecta: a radiographic assessment. Oral Surg Oral Med Oral Pathol Oral Radiol Endod 1999;88:358-364.

3. Korbmacher HM, Lemke R, Kahl-Nieke B. Progressive pre-eruptive crown resorption in autosomal recessive generalized hypoplastic amelogenesis imperfecta. Oral Surg Oral Med Oral Pathol Oral Radiol Endod 2007;104:540544

4. Ooya K, Nalbandian J, Noikura T. Autosomal recessive rough hypoplastic amelogenesis imperfecta. A case report with clinical, light microscopic, radiographic, and electron microscopic observations. Oral Surg Oral Med Oral Pathol 1988;65:449-458.

5. Ravassipour DB, Powell CM, Phillips CL, Hart PS, Hart TC, Boyd C, Wright JT. Variation in dental and skeletal open bite malocclusion in humans with amelogenesis imperfecta. Arch Oral Biol 2005;50:611-623.

6. Seow WK. Dental development in amelogenesis imperfecta: a controlled study. Pediatr Dent 1995;17:26-30.

7. Seymen F, Kiziltan B. Amelogenesis imperfecta: a scanning electron microscopic and histopathologic study. J Clin Pediatr Dent 2002;26:327-335.

8. Bäckman B, Holm AK. Amelogenesis imperfecta: prevalence and incidence in a northern Swedish county. Community Dent Oral Epidemiol 1986;14:43-47.

9. Neville BW, Damm DD, Allen CM, Bouquot JE. Oral \& Maxillofacial Pathology Second Edition. WB Saunders Company. Philadelphia: WB Saunders Company, 2002;89-94.

10. Witkop CJ, Sauk JJ. Heritable defects of enamel. In: Stewart R, Prescott G. Oral Facial Genetics. St. Louis: C.V. Mosby Company, 1976;151-226.

11. Sari T, Usumez A. Restoring function and esthetics in a patient with amelogenesis imperfecta: a clinical report. Prosthet Dent 2003;90:522-525.

12. Winter GB, Lee KW, Johnson NW. Hereditary amelogenesis imperfecta-a rare autosomal dominant type. Br Dent J 1969;127:157-164.

13. Witkop CJ. Partial expression of sex-linked recessive amelogenesis imperfecta in females compatible with the Lyon hypothesis. Oral Surg 1967;23:174-182.

14. Witkop Jr CJ, Kuhlmann W, Sauk J. Autosomal recessive pigmented hypomaturation amelogenesis imperfecta. Report of a kindred. Oral Surg Oral Med Oral Pathol 1973;36:367-382.

15. Haug RH, Ferguson FS. X-linked recessive hypomaturation amelogenesis imperfecta: report of case. J Am Dent Assoc $1981 ; 102: 865-867$.

16. Bedi R. The management of children with amelogenesis imperfecta. Restorative Dent 1989;5:28, 31-34.

17. Bouvier D, Duprez JP, Pirel C, Vincent B. Amelogenesis imperfecta- prosthetic rehabilitation: A clinical report. $J$ Prosthet Dent 1999;82:130-131. 
18. Greenfield R, lacono V, Zove S, Baer P. Periodontal and prosthodontic treatment of amelogenesis imperfecta: a clinical report. J Prosthet Dent 1992;68:572-574.

19. Lumley PJ, Rollings AJ. Amelogenesis imperfecta: a method of reconstruction. Dent Update 1993;20:252-255.

20. Karlsson S, Landahl I, Stegersjo G, Milleding P. A clinical evaluation of ceramic laminate veneers. Int J Prosthodont 1992;5:447-451.

21. Meijering AC, Creughers NH, Roeters FJ, Mulder J. Survival of three types of veneer restorations in a clinical trial: 2.5-year interim evaluation. J Dent 1998;26:563-568.

22. Ozturk N, Sari Z, Ozturk B. An interdisciplinary approach for restoring function and esthetics in a patient with amelogenesis imperfecta and malocclusion: a clinical report. J Prosthet Dent 2004 ;92:112-115.

23. Peumans $M$, Van Meerbeek $B$, Lambrechts $P$, Vanharle G. Porcelain veneers: a review of the literature. $J$ Dent 2000;28:163-177

24. Rucker LM, Richter W, MacEntee M, Richardson A. Porcelain and resin veneers clinically evaluated: 2 year results. $J$ Am Dent Assoc 1990;121:594-596.

25. Zalkind M, Hochman N. Laminate veneer provisional restorations: a clinical report. J Prosthet Dent 1997;77:109-110.

26. Sengün A, Özer F. Restoring function and esthetics in a patient with amelogenesis imperfecta: a case report. Quintessence Int 2002;33:199-204.

27. Fischman SL, Fischman BC. Hypoplastic amelogenesis imperfecta: report of case. J Am Dent Assoc 1967;75:929-931

28. Sanchez-Quevedo MC, Ceballos G, Garcia JM, et al. Dentine structure and mineralization in hipocalcified amelogenesis imperfecta:a quantitative x-ray histochemical study. Oral Dis 2004;10:94-98.

29. Wright TJ, Robinson C, Shore R. Characterization of the enamel ultrastructure and mineral content in hypoplastic amelogenesis imperfecta. Oral Surg Oral Med Oral Pathol 1991;72:594-601.

30. Patel R-RA, Hovijitra S, Kafrawy AH,Bixler D. X-linked (recessive) hypomaturation amelogenesis imperfecta: a prosthodontic, genetic, and histopathologic report. J Prosthet Dent 1991;66:398-402.

31. Hoppenreijs TJ, Voorsmit RA, Freihofer HP. Open bite deformity in amelogenesis imperfecta. Part 1: An analysis of contributory factors and implications for treatment. J Craniomaxillofac Surg 1998;26:260-266.

32. Fritz GW. Amelogenesis imperfecta and multiple impactions. Oral Surg Oral Med Oral Pathol 1981;51:460-462.

33. Williams SA, Ogden AR. Failure of eruption associated with anomalies of the dentition in siblings. Pediatr Dent $1988 ; 10: 130-136$
34. Rowley R, Hill FJ, Winter GB. An investigation of the association between anterior open-bite and amelogenesis imperfecta. Am J Orthod 1982;81:229-235.

35. Aren G, Ozdemir D, Firatli S, Uygur C, Sepet E, Firatli E. Evaluation of oral and systemic manifestations in an amelogenesis imperfecta population. J Dent 2003;31:585-591.

36. Bachmann J. Amelogenesis imperfecta--orthodontic problems and their solution using multiband appliances and temporary steel crowns. Fortschr Kieferorthop 1985;46:6671.

37. Koyutürk AE, Kușgöz A, Șengün A, Ülker M, Sener Y. Micro-shear bond strength of two total-etching adhesives to enamel affected by amelogenesis imperfect. Diş Hekimliği Bilimleri Dergisi 2006;12:77-82

38. Saroḡlu I, Aras S, Oztaș D. Effect of deproteinization on composite bond strength in hypocalcified amelogenesis imperfecta. Oral Dis 2006;12:305-308.

39. Venezie RD, Vadiakas G, Christensen JR, Wright JT. Enamel pretreatment with sodium hypochlorite to enhance bonding in hypocalcified amelogenesis imperfecta: case report and SEM analysis. Pediatr Dent 1994;16:433-436. 